\title{
Gobernanza y evaluación: una relación potencialmente fructífera
}

\author{
Luis F. Aguilar \\ Investigador Nacional Emérito del Sistema Nacional de Investigadores. México \\ luisfaguilar@aol.com \\ María Bustelo \\ Universidad Complutense de Madrid. España \\ mbustelo@cps.ucm.es
}

\begin{abstract}
Resumen
En las tres últimas décadas las dos mayores innovaciones en asuntos de gobierno han sido la Nueva Gestión Pública (modo gerencial o postburocrático), y más recientemente, la Gobernanza o Nueva Gobernanza (modo postgubernamental). Asimismo, el auge de la evaluación de las políticas y los programas públicos es en gran medida resultado de las reformas que los gobiernos por convicción o por fuerza han emprendido en los últimos años y que han modificado sus prácticas, su concepto y sus criterios de valoración. Este artículo constata cómo ha ido tomando forma un nuevo proceso de gobernar y administrar, la (nueva) gobernanza, reconociendo su presencia e importancia directiva, pero también la necesidad y conveniencia de evaluar su actividad y resultados, por lo que indaga en las relaciones que podrían establecerse entre la evaluación y la gobernanza y los beneficios que tanto la gobernanza como la evaluación podrían recibir de sus mutuos aportes.
\end{abstract}

Palabras clave Gobernanza, nueva gobernanza, evaluación, políticas públicas, interés público, desempeño, Administración Pública, partenariados, redes, ciudadanía, acuerdo

\section{Governance and Evaluation: a potentially fruitful relationship}

\begin{abstract}
:
During the last three decades, there have been two major innovations in the field of government affairs, New Public Management (managerial or post-bureaucratic mode), Governance or New Governance (post-governmental mode). Likewise, the new push of program and public policy evaluation, is due in part to reforms that governments have undertaken -by conviction or by force-during these last years, which have modified governmental practices, concepts and assessment criteria. This article discusses how "governance" as a new process of government and administration has taken place, and recognizes its presence and importance as a directive process, and also the need and convenience of evaluating its activities and results. Thus, it investigates on the potential relations between evaluation and governance and the mutual benefits both governance and evaluation might have when their respective contributions are jointly considered.
\end{abstract}

Key words:

Governance, New Governance, evaluation, Public Policy, public interest, performance, Public Administration, Partnerships, networks, citizenship, agreements 


\section{INTRODUCCIÓN}

En las tres últimas décadas las dos mayores innovaciones en el campo de los asuntos de gobierno han sido la estructuración de la nueva administración pública en modo gerencial o postburocrático, la Nueva Gestión Pública, y la configuración de un proceso de gobierno en modo postgubernamental, la Gobernanza o Nueva Gobernanza. El cambio gerencial ocurrido en el modo de administrar, con el propósito de asegurar la costoeficiencia de los programas públicos y mantener finanzas públicas equilibradas, y el cambio gubernativo en modo de asociación o en red con actores privados y sociales, a fin de incrementar o mejorar la capacidad directiva de los gobiernos, han constituido el marco de referencia desde el cual hemos pensado y tratado la actividad directiva de los gobiernos en estos años. Los dos cambios han sido a su vez interdependientes con el cambio estructural de la economía política (o modelo de desarrollo), que tiene en los mercados el fundamento del desarrollo económico de los países y que ha implicado, en consecuencia, la reducción del intervencionismo estatal directo en los procesos económicos. El hecho de que las reformas sean inconclusas, sus resultados sean considerados parciales e irregulares o hayan ocasionado fallas socialmente nocivas, como el crash financiero del 2008 con sus efectos destructivos en la economía real, no ha anulado que sigan siendo el marco de referencia desde el cual no sólo analistas sino gobiernos diseñan sus políticas, instrumentos financieros, servicios y productos.

El auge de la evaluación de las políticas y los programas públicos, que en los últimos años ha expandido notablemente sus actividades, objetivos, objetos, métodos y usos, es en gran medida resultado de las reformas institucionales, fiscales, políticas, económicas y administrativas que los gobiernos por convicción o por fuerza han emprendido en los últimos años y que han modificado sus prácticas, su concepto y sus criterios de valoración. En un primer momento, debido a la necesidad de prevenir o resolver la crisis fiscal de los estados, la costoeficiencia fue el supremo valor administrativo y de gobierno, que exigió el máximo cuidado y aprovechamiento de los recursos públicos a las unidades administrativas responsables de llevar a efecto las políticas y programas y de prestar los servicios públicos. La legalidad o institucionalidad se convirtió en el máximo criterio valorativo de la acción y administración gubernamental en aquellas democracias recientes con problemas crónicos de discrecionalidad, corrupción y opacidad. La eficacia social de los programas gubernamentales se abrió paso y se volvió el principal valor de la actividad de gobierno en aquellos países en los que la eficiencia financiera y la institucionalidad rigurosa no eran suficientes para acreditar o asegurar que los programas producían resultados que modificaban progresiva o significativamente las condiciones sociales de vida de sectores de población o comunidades. Recientemente estos mismos valores sirven de referencia para medir la calidad institucional, económica y gerencial de la (nueva) gobernanza, en respuesta a interrogantes que se preguntan sobre si posee superior eficiencia, eficacia, transparencia y responsabilidad... respecto del tradicional modo gubernamental de dirigir. Sin embargo, la gobernanza suscita además cuestiones sobre su autenticidad pública y su capacidad directiva, que sólo podrán ser aclaradas o zanjadas mediante

24 evaluación, pero a su vez son cuestiones que constituyen un nuevo objeto para los 
ejercicios de evaluación y que renuevan o expanden necesariamente sus métodos habituales o estándares.

El artículo registra que en los últimos años ha ido tomando forma un nuevo proceso de gobernar y administrar, denominado (nueva) gobernanza, cuyas características distintivas se manifiestan en las varias o numerosas acciones que el gobierno lleva a cabo al abordar la solución de los problemas públicos o al realizar determinados objetivos y futuros de valía social. El artículo reconoce la presencia e importancia directiva de la nueva gobernanza, pero también la necesidad y conveniencia de evaluar su actividad y resultados, por lo que indaga en las relaciones que podrían establecerse entre la evaluación y la gobernanza y los beneficios que tanto la gobernanza como la evaluación podrían recibir de sus mutuos aportes. Después de una breve mirada al ejercicio reciente de la evaluación pública y al desarrollo de la disciplina (sección 2) y después de una breve exposición de las características esenciales del proceso y la estructura de la gobernanza (sección 3), el artículo se dedica a trabajar la relación gobernanza-evaluación desde una doble perspectiva, que dará lugar a las secciones 4 y 5 de este artículo.

En estas dos últimas secciones hablaremos primero de la evaluación como componente y herramienta de la gobernanza, pues la evaluación es una actividad indispensable para el aseguramiento y la mejora continua de la dirección de la sociedad por los gobiernos, cualquiera sea el modo directivo. En segundo lugar, plantearemos qué y cómo puede y debe ser evaluada la gobernanza, la cual, en tanto proceso directivo no escapa a la evaluación de su desempeño, a la medición de la calidad, eficacia, eficiencia de sus productos, que son leyes, programas, gasto, proyectos de inversión, servicios. Pero, por otro lado, más allá de la evaluación de su desempeño, la gobernanza suscita varias preguntas acerca de si es un proceso de gobierno posible, si realmente existe y, sobre todo, si es socialmente aceptable y confiable, es decir, plantea preguntas acerca de su existencia real y acerca de su validez pública. Concretamente se trata de preguntas que se interrogan acerca de si las decisiones que se toman y las acciones que se efectúan para abordar un determinado asunto social deban ser consideradas decisiones y acciones en modo de gobernanza (nueva o moderna), así como preguntas acerca de si la gobernanza, por su naturaleza asociada, que incorpora a actores privados y sociales en la decisión y ejecución, no perjudique la naturaleza pública de la acción de gobierno. Hay también preguntas de tipo administrativo o gerencial, que nacen de la preocupación acerca de si el proceso de decisión y efectuación de la gobernanza, en el que participan numerosos actores con diversos intereses, conocimientos y niveles de poder, no complique en vez de facilitar la conducción social, pues si el gobierno de mando jerárquico enfrenta problemas graves de dirección social eficaz es posible pensar que el gobierno en forma de asociación o en red puede ser más fatigoso al momento de tomar decisiones e implementarlas.

\section{HACIA UN ENCUENTRO ENTRE LA EVALUACIÓN Y LA GOBERNANZA}

Una visión panorámica del desarrollo de la evaluación de la acción de gobierno en los últimos treinta años muestra que su aparición y difusión tuvieron razones di- 
versas, vinculadas con diversas situaciones críticas de los gobiernos o con transformaciones notables de su régimen y administración. En algunos países los ejercicios de evaluación aparecieron en los años 70 u 80, en el contexto de los peligrosos déficits financieros que experimentaban numerosos estados sociales en su gasto social y los ponían en riesgo de crisis fiscal. La evaluación fue considerada como el dispositivo analítico y directivo indispensable para conocer y medir las áreas de notoria ineficiencia económica de la acción gubernamental, que ofrecía elementos informativos para prevenir y asegurar la costoeficiencia de las políticas y los programas del gobierno. La evaluación, entendida por parte de algunos sectores como un instrumento de diagnóstico financiero de los programas y organismos gubernamentales, produjo información que fue clave para sanear las finanzas públicas y construir un equilibrio duradero ingreso-gasto público, introduciendo reformas administrativas de compactación de niveles jerárquicos, medición del desempeño y control de gestión y, en casos extremos, de cancelación de programas y organismos, considerados ineficientes.

En continuidad con el valor de la eficiencia, dado que ésta no es sino el modo racional de la eficacia, fue lógico plantearse la cuestión de la eficacia social de las políticas, programas y servicios públicos, por lo que se puso el acento en los resultados, impactos o cambios que producían en la sociedad y se trató de identificar y medir su grado de generación de beneficio o utilidad social: su generación de valor público. Independientemente de la eficiencia económica, la evaluación fue en este enfoque y uso el instrumento empleado para conocer si y en cuánto las diversas acciones de gobierno modificaban las situaciones indeseadas de la realidad social en su conjunto o de sectores particulares de población. Por último, en otros países, particularmente en los de reciente democratización, la evaluación se relacionó con la medición del imperio de la ley y ha sido empleada como sistema métrico para detectar el grado de observancia de la legalidad por parte de los gobiernos y las administraciones públicas, su imparcialidad, trato igual a los ciudadanos. Con este ejercicio se relacionan otras actividades evaluativas cuyo objetivo no es medir la eficacia de las políticas y programas de los gobiernos sino valorar otras características esenciales de la acción del gobierno o de una sociedad, como certidumbre jurídica, respeto de los derechos humanos, gobernabilidad, estabilidad política, desigualdad social, libertad económica, competitividad, riesgo país, capital social, etc., tal como lo practican algunos organismos y fundaciones internacionales cuando realizan estudios con indicadores más o menos robustos para calificar o certificar la calidad de la democracia, la calidad institucional, la calidad de vida, las condiciones económicas y hasta la felicidad de un país. En resumen, las prácticas diversas de la evaluación han contribuido en estas últimas décadas a fabricar o a asegurar la calidad institucional y la calidad gerencial (financiero-administrativa) de los gobiernos.

De este modo, una buena parte de la evaluación de la acción gubernamental realizada en los últimos años se ha ejercido con un conjunto de supuestos, que no son cuestionados y que coinciden en aceptar la relación de causalidad que el diseño y la ejecución de las políticas y programas implican, por lo que la evaluación tiende a con26 centrarse más bien en la medición de los efectos que provocan los comportamientos 
de las organizaciones, unidades o personal de la administración pública, a cuyos aciertos y fallas se imputarán los efectos concretamente. Dicho en términos gruesos, esta evaluación no cuestiona la estructura de causalidad (el teorema, el modelo, la tecnología) de la política y del programa, la supone correcta, siendo los causantes, los operadores, los que son cuestionados.

Los supuestos son específicamente:

a) La corrección del diseño de las políticas, programas y procesos de servicio, suponiendo que la cadena de operaciones de las políticas, programas y servicios implica un ordenamiento claro y preciso de preferencias (objetivos, metas) y una selección de las acciones causalmente idóneas para realizarlas. Al suponer que el diseño de una política o programa contiene una apropiada o correcta relación entre acción-resultado, causa-efecto, medios-fines, la evaluación concentra lógicamente su atención y medición en la actividad, el desempeño, el producto, el resultado, que puede ser inapropiado, deficiente o fallido por errores, defectos e incumplimientos de operación, pero no debido a errores o fallas en el diseño causal de la política. El diseño podrá ser cuestionado posteriormente, a resultas de los datos de la evaluación, particularmente si son alarmantes y si las calamidades que la evaluación señala motivan a que el diagnóstico sobre las causas de los resultados insuficientes o adversos obligue a ir más allá de los comportamientos de los responsables de la operación y examine el diseño mismo y los supuestos de los diseñadores'.

b) Al concentrar su atención en el desempeño gubernamental-administrativo (políticas, programas y servicios), la evaluación puede suponer también tácita o explícitamente que la acción gubernamental posee control suficiente sobre el mundo social y que es la causa social única o determinante, razón por la cual el hecho de que los efectos previstos o esperados no sucedan o no sucedan en el nivel previsto o esperado ha de imputarse de nuevo a defectos de comportamiento de las organizaciones, unidades o personal administrativo del gobierno, sin tomar en consideración las interferencias que las acciones de las autoridades y los servidores públicos pueden haber sufrido por la intervención de otros actores políticos, económicos y civiles, que siguen sus propias lógicas de acción o que han tomado ofensiva o defensivamente partido frente a la decisión gubernamental. En efecto, el actor gubernamental no es único ni determinante en la efectuación de las situaciones sociales preferidas, dado que los contextos sociales están poblados por actores extragubernamentales, cuyos intereses e ideas ponen en movi-

1 Esto mismo se puede afirmar respecto de la evaluación institucional o de la legalidad vigente, cuya corrección normativa es supuesta, aun si sus normas descansan en supuestos causales dudosos acerca de los efectos sociales que producirán la prescripción o la prohibición de determinados comportamientos. Hay leyes incorrectas en la previsión de sus efectos, aun si normativamente vigentes y vinculantes. 
miento sus propias causalidades que facilitan o dificultan la causación gubernamental, la favorecen o la bloquean. En otras palabras, no se reconoce la complejidad de los escenarios pluralistas en los que se desarrolla la acción gubernamental.

c) El tercer supuesto consiste en que los actores clave, decisivos y plenamente responsables son los operadores directos de las políticas y programas, sin destacar que sus acciones y comportamientos se enmarcan en sistemas de acción, pues su operación no ocurre en el vacío ni depende exclusivamente de su habilidad y motivación personal o grupal, sino que está condicionada por estructuras organizativas, jerarquías, normas y reglamentos, pautas de dirección, procedimientos, especificaciones de trabajo, asignaciones de recursos, que proceden de otros niveles y unidades de gobierno sobre los que no tienen control.

En resumen, en muchos casos las evaluaciones se han realizado suponiendo: a) la corrección del diseño causal de las políticas, programas y procesos de servicios; b) la idoneidad de la estructura de organización y dirección de las unidades operativas o del personal que tienen a su cargo la efectuación de las políticas, programas, servicios; c) la dominancia de la causalidad gubernamental sobre la realidad social. Esto explica que sea limitado el número de evaluaciones que, después de listar los efectos y resultados de la acción pública, remitan a examinar escrupulosamente la relación causal que contiene el diseño de la política pública, el tipo de organización pública que es responsable de su implementación y el modo de gobernanza o proceso de gobernar. En mucho, estos supuestos de la evaluación pública van a tenor y son también consecuencia de los enfoques dominantes en las disciplinas de las que parte el planteamiento de la evaluación de la acción pública (tales como finanzas públicas, análisis de políticas públicas y administración pública), que hasta años recientes mantuvieron principios o enfoques de racionalidad estricta, idoneidad organizativa del gobierno ${ }^{2}$ y, sobre todo, suficiencia gubernamental, que consideraba al gobierno dotado de la superioridad y autonomía decisional para realizar por sí mismo el interés y beneficio público

Sin embargo, estos supuestos deben ser reexaminados a la luz de la literatura más reciente sobre políticas públicas y teoría de las organizaciones y de las administraciones públicas, que señalan: a) "la racionalidad limitada" del diseño de las políticas, programas y procesos de servicios, que hace que el diseño, por el lado de sus objetivos y por el lado de sus instrumentos y procesos, esté expuesto intrínsecamente a diferentes definiciones e interpretaciones de los problemas públicos por parte de los diferentes actores que en ellas participan, y, por lo tanto, a inconsistencias, defectos

2 El arreglo jerárquico-burocrático clásico fue considerado la forma organizativa que aseguraba eficacia y eficiencia: la "dominación legal-racional” (Weber), mientras la organización descentralizada o de agencias ejecutivas independientes fue presentada por la Nueva Gestión Pública como la idónea para sus- 
y errores en los aspectos de eficiencia, eficacia e institucionalidad normativa; b) "la contingencia de la organización”, cuya normatividad, estructura, pautas de dirección y especificaciones de operación, en su conjunto o por separado, pueden o no asegurar la implementación y gestión eficaz de la políticas, programas y servicios; c) "el enfoque gubernamental(ista)", es decir la idea de que el gobierno es suficiente en la solución de los problemas sociales y en la producción de los objetivos sociales preferidos, por lo que tanto el éxito como el fracaso relativo es atribuible exclusivamente al gobierno, sus organismos y su personal, con las correspondientes exaltaciones o escepticismos respecto de los alcances del gobierno. En resumen, parece existir una paradoja metodológica u operativa en los ejercicios estándar de la evaluación. Sus supuestos no consideran los límites del gobierno, sus límites de racionalidad directiva, no obstante su gran número de poderes y recursos, mientras sus resultados informan permanentemente acerca de los límites de análisis, estructura, dirección y operación de los gobiernos.

Para un replanteamiento de la evaluación es importante registrar sus límites, que no son reconocidos por los enfoques más tradicionales que asumen inercialmente perspectivas que nos llevan a un callejón sin salida en la relación gobernanza-evaluación, pero también destacar varios elementos a favor que nos permiten ser algo más optimistas para un encuentro productivo de ambos conceptos, que ahora apuntamos y a los que posteriormente apelaremos a lo largo del desarrollo del artículo. Nos referimos, en primer lugar, a la propia historia y desarrollo del campo de la evaluación en la que podemos encontrar muchas referencias tanto teóricas como prácticas, y que no siempre se han aplicado, o se han aplicado muy limitada y anecdóticamente a la evaluación de la acción gubernamental en muchos de nuestros países. Efectivamente, con el empuje inicial de los países anglosajones, la evaluación se ha ido convirtiendo en un campo profesional y académico de creciente interés y bajo el cual se han desarrollado y desarrollan todo un elenco de teorías y enfoques que suponen un cuerpo teórico y práctico que puede arrojar luz a una utilización cabal de la evaluación en el ámbito de la gobernanza (Stufflebeam y Shinkfield, 1987; Stufflebeam, 2001; Stufflebeam; Madaus y Kellaghan, 2002; Bustelo, 2001). De hecho, si se hace un análisis histórico de los enfoques de evaluación, se puede observar como se trata de un campo que más que moverse y desarrollarse a través de modelos teóricos, ha ido intentando dar solución a los retos y problemas prácticos que planteaba la aplicación de una evaluación tradicional y lineal a la acción pública que pretendía actuar sobre una realidad social cada vez más compleja y fragmentada (Ballart, 1996; Shadish, Cook y Levinton, 1991; Weiss, 1998).

En segundo lugar, quisiéramos mencionar la ampliación creciente tanto del objeto como de los usos de la evaluación. Bajo los enfoques más racionalistas en los que se concebía el proceso de elaboración de las políticas públicas como un proceso ordenado y claro en sus diferentes fases, parecía lógico que se reservara el objeto de evaluación principalmente a los resultados de las políticas -se controlaba la formulación con un buen análisis de la realidad y unas técnicas adecuadas de planificación, se controlaban también los procesos de implementación que en parte se daban por estableci- 
dos desde el diseño y la toma de decisiones, por lo que a la evaluación le quedaba controlar que se habían conseguido los efectos deseados previamente planificados y debidamente implementados-. Pero paralelamente al propio reconocimiento de la racionalidad limitada de las políticas, se entiende que hay que evaluar más aspectos o componentes de las mismas, ampliando así el objeto de evaluación tanto a los procesos de implementación, como al propio diseño y formulación de las políticas (Bustelo, 2001). Asimismo, se va reconociendo el papel de la evaluación no sólo como facilitadora de las decisiones gubernamentales sino como elemento clave en el aprendizaje de las organizaciones, ampliando así el concepto de uso instrumental (utilización de la información que arroja una evaluación para tomar decisiones sobre la acción evaluada), a otros tipos de uso, como son el conceptual (contribuyendo a la definición de conceptos), persuasivo (para conseguir apoyos necesarios) o académico-profesional (contribuyendo al acervo científico de una comunidad) (Weiss, 1998). Incluso se ha llegado a apelar a los efectos que la propia evaluación puede tener en la creación de sistemas y metodologías futuras de evaluación así como de cultura evaluativa (Torres, Preskill y Piontek, 1996).

Por último, también resulta de especial interés la ampliación reciente del campo de aplicación de la evaluación de las acciones de gobierno, en concreto la consideración de la evaluación como instrumento de fomento y profundización de la democracia y que va unida a una creciente institucionalización de la función de evaluación en los gobiernos y las administraciones públicas. De esta manera se comienza a concebir la evaluación como una forma de aumentar la rendición de cuentas a la ciudadanía y la calidad democrática a través de la transparencia y la participación. Como ejemplo, éste es uno de los principales propósitos declarados de la Agencia Estatal de Evaluación de Políticas Públicas y Calidad de los Servicios (AEVAL) creada por el Gobierno Central español en 2006 (Garde, 2007). A la creación de unidades o agencias especializadas en la evaluación de la acción de gobierno (en el caso español, además de la AEVAL, se pueden mencionar ejemplos de unidades sectoriales -como la DGPOLDE 3 en el sector de la cooperación internacional-o descentralizadas -como IVALUA ${ }^{4}$ en gobierno autonómico catalán-), habría que añadir otros indicadores de institucionalización de la función de evaluación, y que pueden favorecer nuestro análisis, como

3 DGPOLDE: Dirección General de Planificación y Evaluación de Políticas de Desarrollo, dependiente de la Secretaría de Estado de Cooperación Internacional del Ministerio de Asuntos Exteriores. Es de su competencia llevar a cabo tareas de formulación, planificación, seguimiento y evaluación de la política española de cooperación internacional para el desarrollo, y entre sus funciones se encuentran desarrollar las labores de seguimiento, coordinación y evaluación de la ayuda española oficial para el desarrollo, y evaluar las políticas, instrumentos, intervenciones, programas y proyectos de cooperación internacional.

4 IVÀLUA es un consorcio público, en el que participan la Generalitat de Catalunya, la Diputació de Barcelona, la Universitat Pompeu Fabra y la Fundació Jaime Bofill, y cuya misión es promover la evaluación de las políticas públicas en el ámbito autonómico y local, para contribuir a la mejora de la acción de gobierno y de sus efectos en la vida de los ciudadanos y ciudadanas de Cataluña. Sus cuatro ejes de actuación son el fomento de la demanda y utilización efectiva de la evaluación de políticas públicas por parte de directivos y gestores públicos, la articulación de un modelo de evaluación de políticas públicas en Cataluña, en colaboración con el resto de actores presentes en este ámbito, la promoción de la oferta y del conocimiento existente en relación con la evaluación de políticas públicas en Cataluña, y la mejora de la información a la ciudadanía y de su participación en la valoración de políticas públicas autonómicas y locales. 
son la creación de asociaciones profesionales de evaluación nacionales y supranacionales (como ejemplo, Sociedad Europea de Evaluación creada en 1996 y Sociedad Española de Evaluación creada en 2001) ${ }^{5}$, la puesta en marcha de formación de postgrado específica ${ }^{6}$, la producción de literatura y materiales de evaluación -tanto libros y manuales, como revistas especializadas, como guías y orientaciones metodológicas-, así como la propia práctica de evaluación y la existencia de estudios de procesos de evaluación, la cual genera un "mercado" de trabajo en el que se integran diferentes actores tales como evaluadores/as, clientes, comanditarios/as y gestores/as de evaluaciones (Bustelo y Fitzpatrick, 2009).

\section{LA GOBERNANZA: MEMORÁNDUM SOBRE SU PROCESO Y ESTRUCTURA}

Los ejercicios de evaluación han arrojado información abundante y relevante sobre el nivel o grado de eficacia directiva de los gobiernos, un tema que se ha vuelto recientemente de gran importancia cognoscitiva y cívica. La cuestión de la capacidad y eficacia directiva de los gobiernos se ha colocado en los últimos años en el centro de la preocupación de la ciudadanía, inconforme o desilusionada por los insuficientes o hasta nulos rendimientos de los gobiernos en varios asuntos que consideran cruciales para sus vidas, y también en el centro de las disciplinas que tienen a la acción del gobierno como su objeto de conocimiento. Para el planteamiento de la cuestión y aun para sus líneas de solución han sido fundamentales el ejercicio y los resultados de las evaluaciones, que han tenido un doble efecto. Por un lado, la información que la evaluación proporciona sobre el número y la magnitud de las deficiencias de los varios programas públicos ha indeliberadamente reforzado el escepticismo de muchos ciudadanos sobre la capacidad del gobierno para atender asuntos importantes de interés general. Por otro lado, el análisis del desempeño gubernamental y la medición de sus consecuencias sociales han servido para identificar con mayor precisión las áreas problemáticas del gobierno, corregir errores, anticipar ineficiencias y, en la práctica, mejorar la capacidad directiva gubernamental.

Los problemas de eficacia directiva de los gobiernos han tenido dos líneas generales de respuesta: la gobernabilidad y la gobernanza. Son dos enfoques conceptuales y prácticos que se relacionan ambos con la acción del gobierno, hacen referencia al problema de la capacidad directiva del gobierno y buscan su solución, pero tienen un diverso planteamiento del problema y ofrecen una diversa respuesta, aunque los dos enfoques sean complementarios y el enfoque de la gobernanza integre el enfoque de la gobernabilidad, que pone el acento en las capacidades del gobierno como una de sus condiciones necesarias de dirección social. Dicho resumidamente, el enfoque de gobernabilidad considera que el problema directivo es suficientemente resuelto si se dota o se provee de nuevo al gobierno con las capacidades requeridas (instituciona-

\footnotetext{
5 Ver http://www.europeanevaluation.org/ y http://www.sociedadevaluacion.org/website/

6 En el caso español, Magíster en Evaluación de Programas y Políticas Públicas de la UCM, desde 2002 y Master Latinoamericano en Evaluación de Políticas Públicas de la UNIA desde 2007.
} 
les, fiscales, administrativas, coactivas...) para estar en aptitud de dirigir a la sociedad, mientras el enfoque de gobernanza apunta a la necesidad o conveniencia de practicar un nuevo proceso directivo de la sociedad. Mientras el enfoque de la gobernabilidad supone que un gobierno capaz, dotado con las capacidades requeridas, es suficiente para dirigir a la sociedad, el supuesto básico de la gobernanza es la noción de que en las condiciones de la sociedad contemporánea (nacional e internacional) el gobierno es un agente de dirección necesario pero insuficiente, aun si dispusiera de todas las capacidades requeridas y aun si sus acciones aprovecharan a cabalidad las muchas capacidades que le han sido otorgadas o se le pudieran otorgar. La insuficiencia gubernamental para definir y sobre todo realizar los futuros preferidos de sociedad hace que los gobiernos requieran y valoren las capacidades de la sociedad económica y civil, particularmente en los asuntos de crecimiento económico y bienestar o seguridad social universal, lo cual introduce otro tipo de relación entre el gobierno y la sociedad y obliga al gobierno a practicar otro modo de gobernar a la sociedad. 7

En términos generales, por gobernanza se entiende el proceso o la actividad de gobierno o dirección de la sociedad. Por ser una actividad directiva, la gobernanza es una actividad intencional, orientada a la realización de los objetivos sociales preferidos, y es una actividad causal, en tanto es la acción considerada idónea para realizar los objetivos preferidos. La intencionalidad de la gobernanza hace referencia a valores, objetivos, futuros, preferencias sociales y la causalidad implica recursos, instrumentos, acciones, formas de organización y gestión. La gobernanza es entonces una actividad directiva estructurada valorativamente (institucionalmente) y técnicamente. La influencia del gobierno y la sociedad en la definición y ejecución del contenido de la gobernanza (es decir, de sus objetivos, instrumentos, acciones... ) para conducir una determinada situación social es mayor o menor según circunstancias sociales específicas, según el tipo de asuntos públicos que abordan y, en el fondo, según la estructura política existente de relaciones entre el gobierno y la sociedad. El peso cambiante del gobierno o de la sociedad en la definición del contenido de la gobernanza es el criterio fundamental de los diversos tipos de gobernanza en la sociedad ${ }^{8}$, y la averiguación realmente relevante tanto para fines cognoscitivos como políticos.

En términos específicos, por gobernanza "nueva" o "moderna" (o gobernanza en sentido estricto) se entiende el proceso de dirección de la sociedad cuya intencionalidad y causalidad es definida y realizada por el gobierno en interdependencia (en asociación o en red) con las organizaciones económicas y sociales, en razón de que el gobierno en las condiciones económicas y sociales actuales (global-nacionales) care-

7 Para un desarrollo analíticamente más preciso y fundado de la Gobernanza, me permito remitir a las obras de Aguilar (2007, 2009); Innerarity (2006), Natera (2004), Prats (2004) en el medio español y latinoamericano. En el ámbito internacional son fundamentales Kooiman (1993, 2003), Rhodes (1997), Pierre (2000), Bevir (2009), entre otros.

8 Kooiman ha propuesto tres tipos: "gobernanza jerárquica” o por el gobierno, "gobernanza por autogobierno" y “gobernanza por cogobierno", llamada ésta “nueva, moderna gobernanza”, en el entendido que los modos empíricamente observables de gobierno de la sociedad manifiestan en diversos grados los atributos esenciales de los tipos puros de gobernanza o los combinan. 
ce de los recursos suficientes (financieros, cognoscitivos, tecnológicos, políticos...) para definir y realizar por sí mismo el sentido de dirección de su sociedad, a consecuencia de que la consolidación de la democracia ha expandido la esfera de la deliberación pública y la participación de los ciudadanos en los asuntos públicos, y a consecuencia de que sectores clave de la sociedad económica y civil (global-nacional) poseen la independencia política y la autonomía ejecutiva suficiente para hacerse cargo de sus asuntos y resolver sus problemas, para resistirse a decisiones de gobierno adversas a sus planes o eludirlas y para exigir tomar parte en la definición de la orientación de la sociedad y colaborar en su efectuación.

Al momento de su aparición la gobernanza, en el sentido específico de gobernanza nueva o moderna, fue básicamente un concepto descriptivo, que describía el comportamiento que estaban siguiendo los gobiernos sociales de numerosos países, a partir de los años 80 y 90, a raíz de las reformas financieras y administrativas que emprendieron para prevenir o superar su crisis fiscal y que tuvieron como efecto modificar la estructura administrativa del gobierno y su modo tradicional de gobernar. El comportamiento directivo y administrativo del gobierno mostraba que había dejado de ser el actor único o dominante, que mediante sus burocracias formula y lleva a cabo las políticas públicas y los servicios públicos y, en cambio, se podía observar que definía sus políticas y realizaba sus tareas públicas mediante variadas formas de colaboración y asociación con actores privados y sociales o que había aceptado y hasta formalizado institucionalmente que las organizaciones privadas y sociales se hicieran cargo de la efectuación de ciertas políticas y servicios, sin intervenir en modo directo en su operación, aun si en estos casos el gobierno establecía con frecuencia las normas y estándares de operación, producto y resultado y muy probablemente las financiaba y evaluaba su desempeño.

El nuevo proceso directivo es descrito como un paso de las formas directas de gobierno hacia las "formas indirectas" o "mediante terceros" o de "gobierno a distancia" y también como un cambio del modo jerárquico de gobernar mediante mando y control de las organizaciones económicas y sociales hacia uno más descentralizado, horizontal, interdependiente, relacional, interactivo, participativo, consensual, en forma de red con las organizaciones sociales ("gobierno por redes, en red"). Las definiciones descriptivas destacan además las formas de diálogo y negociación que practican los actores públicos y privados para ajustar sus intereses, conciliar sus diferencias y llegar a los acuerdos básicos que serán el marco de referencia para elaborar las políticas y prestar los servicios públicos de beneficio social o para decidir políticas estratégicas y proyectos de inversión cruciales para la viabilidad y prosperidad de la sociedad. En resumen, Gobernanza representa las formas de un gobernar nuevo, descentralizado, asociado, con la consecuencia de que gobierno y sociedad sin perder su diferencia e independencia coproducen ahora un buen número de políticas, inversiones, proyectos y servicios públicos, definiendo cómo se dividirán el trabajo, la autoridad y la responsabilidad y qué cantidad y tipo de recursos aportarán tanto el gobierno como las organizaciones económicas y civiles a fin de realizar los objetivos sociales preferidos. 
Gobernanza se volvió posteriormente un concepto teórico, cuando su modo o patrón de gobernar se presentó como el efecto de transformaciones económicas, sociales y gubernamentales de magnitud estructural (no coyunturales) y se le argumentó como el modo de gobernar apropiado en las condiciones sociales actuales, que otorga capacidad y eficacia directiva a los gobiernos y contribuye a reconstruir su significación social y la confianza ciudadana. El principio o supuesto cognoscitivo en el que se sustenta la gobernanza es el enunciado de la pérdida relativa de autonomía, soberanía, centralidad, control del gobierno (términos usados en la literatura) sobre la dinámica económica contemporánea, cuyo motor son las firmas globales y las cadenas de valor internacionales, y sobre el pluralismo de las posiciones políticas, intelectuales y morales que caracteriza la vida de la sociedad. La insuficiencia o limitación directiva del gobierno en la nueva estructura y economía política de la sociedad tiene como efecto que el gobierno ya no puede definir y realizar por sí mismo el rumbo de su sociedad y origina una forma de dirigencia interdependiente y asociada con actores extragubernamentales, un "sistema de gobernanza" (PNUD), en el que el gobierno es agente indispensable y fundamental pero ha dejado de ser el protagonista unilateral y determinante.

El proceso de gobernar tiene su estructura, no es una actividad sin restricciones, discrecional, que puede reinventarse en cualquier momento. En las democracias modernas el gobernar es un proceso estructurado institucional y técnicamente. Lo normal es que las normas legales y las normas técnicas enmarquen y encaucen las decisiones y operaciones del gobernar, por lo que es identificable un patrón de comportamiento directivo, no obstante las variaciones políticas de interlocución gubernamental-social a las que obligan las cambiantes situaciones sociales y los diversos asuntos públicos. Es objeto de investigación empírica averiguar cuáles son los componentes concretos que integran la estructura del gobernar de un particular gobierno en una determinada circunstancia o frente a un determinado asunto, pero es también posible enunciar teóricamente los componentes esenciales de la estructura de la gobernanza nueva, puesto que sin ellos no podría existir, desarrollarse y realizar con eficacia la conducción social.

Los componentes estructurales son de dos tipos, institucionales y técnicos. Los factores o componentes institucionales de la gobernanza nueva son: las instituciones de los poderes públicos (que definen su titularidad y modo de ejercicio), el sistema de justicia y seguridad, las instituciones del mercado, las de la sociedad civil y las instituciones internacionales ${ }^{9}$, mientras sus componentes técnicos son el sistema de ciencia-

9 Un componente estructural de la gobernanza que tiene importancia creciente en todos los estados es el de las instituciones internacionales (sus regímenes y sus organismos ejecutivos), que incluyen en modo paradigmático las asociaciones políticas supranacionales, como la UE. Los gobiernos de los estados nación gobiernan cada vez más en conformidad con regímenes, reglas, acuerdos, convenios, protocolos, estándares de políticas y servicios públicos que son de validez internacional, en el entendido de que las instituciones internacionales se articulan con la tendencia de la economía global, cuyos actores privados 34 significativos producen también normas técnicas y comportamentales que son vinculantes para el intercambio económico y para participar en las cadenas de valor internacionales. 
tecnología, las finanzas públicas, las políticas públicas y la administración pública. Los componentes institucionales son fundamentales para la validez social del proceso directivo ("legitimidad política"), mientras los componentes técnicos son básicos para asegurar suficientemente que el proceso directivo sea productivo, eficaz. Estos dos tipos y planos de componentes, según sea su contenido, son los factores que crean y definen la capacidad y eficacia directiva de los gobiernos, la amplían o restringen, la facilitan o dificultan, la normalizan ${ }^{10}$.

Los componentes de la estructura de la gobernanza demarcan el alcance de las capacidades gubernamentales, lo que el gobierno puede hacer, pero su aprovechamiento cabal y su empleo eficaz depende de las prácticas políticas que lleven a cabo los gobernantes, es decir, del número y tipo de relaciones que establezcan y estabilicen con los varios sectores de la sociedad, particularmente con aquellos que por las capacidades y recursos que poseen son necesarios y relevantes para resolver los problemas sociales crónicos y producir los futuros deseados. Las prácticas políticas son conocidas y remiten al conjunto de convocatorias, consultas, diálogos, discusiones, negociaciones, ajustes mutuos, acuerdos, conciliaciones, compromisos, treguas... (y también comportamientos opuestos) que tienen lugar entre gobierno y organizaciones políticas, económicas y sociales. Sin embargo, aunque el proceso de gobierno esté coherentemente estructurado y el diseño normativo (institucional y técnico) de sus factores constitutivos sea el apropiado para que el gobierno posea capacidad directiva, puede ocurrir que el gobierno no muestre habilidad interlocutoria, disposición a coordinarse y acordar, al momento de relacionarse con los diferentes actores políticos, económicos y sociales, con la consecuencia de suscitar críticas, enfrentamientos, deserciones y desaprovechar o subutilizar las mejores capacidades de su estructura gubernativa.

Las prácticas políticas que el gobierno lleva a cabo para definir y ejecutar la conducción social es lo que la gobernanza vindica y justifica. Por eso pone el acento en la necesidad y conveniencia de un nuevo proceso directivo, de una nueva relación entre gobierno y sociedad para abordar los asuntos de interés general. Las poderosas capacidades legales, fiscales y administrativas de las que dispone el gobierno pueden quedar paralizadas o no tener los alcances que podrían tener si las prácticas políticas de los gobiernos con los otros poderes públicos, los otros gobiernos, las firmas empresariales, las organizaciones sociales, los centros de conocimiento son impertinentes. En general, esto ocurre si el gobierno no es, en primer lugar, un gobierno suficientemente unitario y coherente en su actividad directiva (integración y coherencia de sus políticas, programas y organismos) y si sigue encerrado en un principio rígido de protagonismo y superioridad, con la pretensión de querer subordinar a la sociedad en vez de coordinarse con ella y coordinarla. En su lugar las prácticas políticas nuevas, que posibilitan una gobernación más eficaz, son las que se orientan a motivar y persuadir a los poderes públicos y a las organizaciones sociales a cooperar y coproducir

10 En el contexto de este artículo, los componentes institucionales y técnicos de la gobernanza son enunciados y no desarrollados. 
una posición compartida en los asuntos de crecimiento económico y desarrollo social, ${ }^{11}$ a dar forma a un modo de gobierno en red, en asociación, en la que el gobierno es un actor necesario con funciones de convocador, facilitador, animador y coordinador, pero ya no el epicentro de la conducción de la sociedad.

\section{LA EVALUACIÓN COMO ELEMENTO CLAVE DE LA GOBERNANZA}

La evaluación es la recopilación y análisis sistemático de información, a través de unos criterios previamente establecidos, con la intención de emitir juicios -también probados y sistemáticos- sobre el valor y/o mérito de lo que se está evaluando, en este caso la actividad y los resultados de la gobernanza pública. La evaluación tiene un claro carácter práctico y aplicado y su sentido último se encuentra en la utilidad potencial que dicha actividad tiene para las decisiones directivas, gerenciales u operativas de varios tipos y alcance. En este sentido, a la evaluación se le reconocen tres funciones claras ${ }^{12}$ no excluyentes entre sí y que la dotan de sentido y significado, especialmente si hablamos de la evaluación de la acción pública, es decir de las diferentes actuaciones promovidas por los gobiernos para abordar y solucionar los problemas de la ciudadanía. La primera de las funciones, de carácter más técnico, es la de aprendizaje o mejora (improvement), por la que la evaluación sirve para aprender sobre la propia práctica y mejorar la acción futura. En este sentido la evaluación cumple el papel de informar sobre las potencialidades y dificultades de una determinada acción, con el fin de utilizar dicha información para introducir cambios y mejoras en dicha acción. La segunda, de carácter más político, es la de rendición de cuentas (accountability), o para ser más exactos y dejar claro que no hablamos sólo del control económico, fiscal y contable de las acciones públicas, de la rendición de responsabilidades. Según esta función, la evaluación cumple el papel de rendir cuentas a la ciudadanía y a los actores involucrados sobre cómo se han empleado los fondos públicos, se ha interpretado el interés general y se ha dado (o intentado dar) solución a las diversas demandas de la ciudadanía. Por último, la tercera función, si se quiere de un carácter más “científico”, es la de iluminar acciones futuras (enlightenment). Así, aun-

11 En el campo de la gobernanza hay que distinguir entre las acciones del gobierno relacionadas con el aseguramiento del orden público / seguridad pública y las actividades relacionadas con el bienestar y el desarrollo de su sociedad. Las primeras, las esenciales del estado, no pueden ser llevadas a cabo más que en modo de "vieja gobernanza" o de "gobernanza jerárquica” o “por gobierno", en tanto el Estado es la organización soberana que se distingue por poseer legítimamente la coacción en su sociedad territorial sin compartir su fuerza con nadie y está obligado a neutralizar, sancionar y derrotar a los grupos o personas que en modo violento lesionan personas, libertades y propiedades de sus ciudadanos en su ámbito territorial o a los grupos que quieren convertirse en un poder territorial alternativo. En cambio en los temas de crecimiento económico y desarrollo social son limitadas las capacidades del estado, de modo que sin el aporte de la sociedad económica y civil, cuyos recursos financieros, tecnológicos y organizativos son clave para la productividad, la competitividad y la prosperidad, no está en condiciones de dirigir a su sociedad.

12 Las tres funciones de la evaluación tal y como aquí se describen son básicamente reconocidas por diferentes autores/as con diferentes matices. Para una ampliación del tema sobre la definición y funciones de evaluación, ver Stufflebeam y Shinkfield, 1987; Vedung, 1997, Bustelo, 2003. 
que el principal fin de la evaluación no es el de la construcción de conocimiento (en eso se diferencia de la función de investigación), lo que sí es cierto es que la evaluación contribuye a un aprendizaje a más largo plazo y que trasciende a las enseñanzas sobre una acción concreta, “iluminando” así la acción pública general, el mayor conocimiento y comprensión de la realidad y las mejores maneras y estrategias generales para actuar sobre la misma.

La evaluación es (o debería ser), por lo tanto, una pieza importante de cualquier acción pública, ya que las funciones de mejora, rendición de cuentas e iluminación para acciones futuras pueden considerarse requerimientos intrínsecos de la actuación pública. Pero además, en el caso de la gobernanza, creemos que puede apelarse a tres razones por las que la evaluación es una pieza clave para refinar y consolidar el enfoque directivo público-privado, gubernamental-social de la gobernanza, que suscita problemas políticos relacionados con la naturaleza y responsabilidad pública de sus decisiones y acciones, así como problemas gerenciales relacionados con la tarea de coordinar el conjunto diferenciado de actores que participan en la deliberación, decisión y ejecución del contenido de la gobernanza (objetivos, instrumentos, acciones, recursos, tiempos...).

El carácter asociado de la gobernanza plantea de inmediato la cuestión de cómo el gobierno puede llevar a cabo la coordinación de los diferentes actores que participan en el diseño y la implementación del contenido de la gobernanza, coordinación que se vuelve una actividad crucial para integrar las posiciones y los recursos de múltiples actores con diferentes niveles de conocimiento y poder y llegar a definir la propuesta de cómo se gobernarán ciertas situaciones sociales problemáticas o cómo se movilizarán las potencialidades sociales para realizar objetivos sociales relevantes. La tarea "transversal” de la función de coordinación está en total sintonía con la función de la evaluación, pues los métodos y resultados del ejercicio evaluativo son especialmente útiles para: a) obtener información acerca de todos y cada uno de los diferentes actores involucrados, b) palpar sus necesidades y demandas, c) tener una panorámica global del mapa de actores y de sus relaciones de interdependencia, d) conocer los resultados que han tenido diseños y decisiones de política similares a las que están por tomar asociadamente gobierno y sociedad, y e) retroalimentar el funcionamiento en red y la relación de los actores gubernamentales, privados y sociales. Al ser la gobernanza un modo de gobierno más descentralizado, horizontal, interdependiente y consensual, las decisiones que gobierno y actores sociales toman asociadamente para dirigir a la sociedad ya no pueden ser mediante el mando del gobierno y la subordinación de los participantes sino mediante la información más objetiva posible, oportuna y relevante sobre el proceso decisorio asociado o en red (sus conceptos, argumentos, cálculos, intereses, propuestas...) y sobre los probables efectos sociales de la decisión. La información ofrece elementos al gobierno para que esté en aptitud de coordinar la interacción de los múltiples actores participantes, la cual no necesariamente será tersa, consonante, cooperativa y concluyente. La evaluación es entonces imprescindible como función sistemática de recopilación y valoración de información relevante para que el actor gobierno pueda coordinar el proceso me- 
diante el cual los actores sociales y él mismo deciden el modo cómo se atacarán los problemas públicos y se realizarán los objetivos públicos deseados. En suma, la evaluación, al arrojar información sobre los efectos que tienen ciertas acciones para facilitar el entendimiento entre los actores participantes y sobre los efectos que tendrá la implementación de la decisión tomada para resolver los problemas y realizar los objetivos públicos deseados, es un instrumento fundamental para facilitar la coordinación gubernamental del proceso decisorio en red o en asociación.

Efectivamente, esta forma más relacional no implica que los gobiernos no sigan siendo los principales responsables de la acción pública, sino que los gobiernos ejercen su papel directivo en modos diferentes a los tradicionales de jerarquía mediante mando y control. La gobernanza es un proceso de dirección que, por ser una acción colectiva en la que participan múltiples actores en el diseño y realización de sus objetivos, requiere (genera o dispone de) una instancia / agencia de gobierno con la función de resolver o facilitar la solución de los problemas centrales de toda acción colectiva, que requieren se controle tanto el conflicto como el parasitismo y oportunismo que anidan en la acción colectiva. Esto parece más imprescindible aún si este modo de gobernar implica el paso a formas de gobierno más indirectas, mediante terceros o de gobiernos a distancia. El hecho de que se concierte la prestación de servicios o la realización de proyectos de infraestructura con empresas privadas u organizaciones sociales no significa que los poderes públicos no tengan la responsabilidad última de la realización eficaz y responsable de la provisión de determinados bienes y servicios públicos, teniendo que empeñarse de manera especial, en el seguimiento y la evaluación de la prestación'13.

En este sentido, conviene dejar establecido con claridad que el contenido de la gobernanza es ciertamente el resultado conjunto de los aportes (informativos, cognoscitivos, tecnológicos, financieros, normativos, organizativos...) que hacen los participantes gubernamentales y privados o sociales en su proceso de elaboración, pero el aporte específico, original y único del gobierno es otorgar carácter público al contenido coproducido en asociación con los actores privados. El hecho de que el poder público legítimo acepte el resultado de la deliberación conjunta, haga suyo el acuerdo conclusivo, es lo que hace que la gobernanza tenga valor público, sea decisión pública y, en este sentido, sea vinculante. En los temas de gobernanza, al igual que en otros casos similares de acción pública, la naturaleza pública de la decisión y su ejecución no se ubica en el contenido o en la materia de la decisión sino en su forma pública, la cual le es otorgada por la aceptación del poder público. Puede haber asociación, red, sistema, colegialidad en la producción del contenido de la gobernan-

13 Todavía está por realizar una evaluación sistemática de lo que ha supuesto la concertación masiva de empresas privadas para la prestación de servicios públicos de carácter social, educativo y cultural en muchas administraciones locales españolas. La Fundación catalana Pi i Sunyer, está realizando un estudio a través de su Observatorio de Gobierno Local sobre los municipios catalanes, en el que introduce el análisis y evaluación de dichas concertaciones. Ver http://www.observatorigovernlocal.org/. Para una discusión sobre la evaluación de los servicios públicos externalizados ver Sancho, 2009. 
za, pero ésta llega a ser pública sólo mediante la sanción del poder público. El gobierno da la forma pública (de ley, decreto, política, programa, servicio, inversión, acción... ) al contenido de la decisión en cuya elaboración el gobierno tuvo como socios a actores no gubernamentales. En definitiva, el gobierno es o debe ser el principal garante de una acción pública que dé respuesta a las necesidades y demandas sociales, y es quien está finalmente legitimado democráticamente para interpretar y dar forma al interés general de la ciudadanía.

Por último, la tercera razón que hace de la evaluación un elemento clave de la gobernanza es la transparencia. La eficacia de una política, programa, servicio, proyecto de inversión depende no sólo de su idoneidad técnica y costoeficiencia para producir los resultados deseados, sino también de su validez política, que en gran medida va a estar determinada por la valoración y aceptación social de su contenido (medios-fines, causas-efectos, acciones-resultados) y particularmente del proceso mediante el cual se llegó a decidir éste y no otro contenido, lo cual implica la exigencia ciudadana de saber cuáles fueron los requisitos de acceso al proceso decisorio, el perfil de los participantes, las reglas o prácticas de deliberación, negociación y acuerdo que establecieron los participantes, el papel que jugó la instancia de gobierno a lo largo del proceso... Puede ser que la aceptabilidad social sea fácil y hasta rutinaria en las acciones gubernamentales que atienden asuntos ordinarios o de limitada importancia general, pero se vuelve una aprobación compleja y aun controversial en el momento en que los gobiernos encaran problemas sociales crónicos, asuntos críticos y futuros cruciales de sociedad, por lo que se deben tomar decisiones directivas extraordinarias. En estos casos es lógico y justificado que la ciudadanía preste atención al contenido de la decisión pero, sobre todo, quiera conocer el modo como se procesó la decisión, indagando sobre los actores que participaron en su elaboración, los argumentos que utilizaron y las prácticas que siguieron para alcanzar una conclusión y comprometerse con ella, y finalmente quiera saber la posición que sostuvo el gobierno y las razones por las que aceptó que las conclusiones o los acuerdos eran públicamente importantes y beneficiosos. En consecuencia, esto significa la exigencia ciudadana de que se transparente el proceso, de hacerlo accesible a los ojos de los ciudadanos, y de que los decisores, más allá de las peripecias del proceso, ofrezcan razones de por qué llegaron a concluir que sus decisiones tenían mayor sentido y beneficio público en vez de otras opciones teóricamente posibles y que además estaban presentes en la sociedad con voces relevantes y argumentos serios. Evidentemente, la evaluación cumple un papel fundamental en el ejercicio de dicha transparencia.

En definitiva, el enfoque de la gobernanza exige a su vez un enfoque de evaluación de corte pluralista y participativo. Más allá de la legitimidad institucional y de la validez científico-técnica, el modo de dirección de los gobiernos deberá aplicar una evaluación con criterios de legitimidad política y utilidad social que implica necesariamente la participación de los diferentes actores gubernamentales y no gubernamentales presentes en el modo de gobierno (para profundizar en los enfoques pluralistas de evaluación, véase Monnier, 1996) 


\section{5. ¿QUÉ Y CÓMO SE PUEDE EVALUAR LA GOBERNANZA?}

La nueva gobernanza se ha ido afirmando en la práctica y aun en el concepto como el modo de gobierno apropiado para abordar numerosos asuntos públicos de la sociedad contemporánea. Sin embargo, al mismo tiempo, han surgido interrogantes y preocupaciones acerca de la validez pública o institucional de la dirección asociada o en red y asimismo acerca de su validez técnica y gerencial. Por un lado, hay dudas y cuestionamientos acerca de la naturaleza pública o validez político-institucional de la gobernanza como actividad de gobierno y, en consecuencia, sobre el carácter vinculante de sus decisiones para la sociedad. ${ }^{14}$ Por otro lado, hay un grupo de preguntas de índole más tecno-administrativa, que se enfocan a examinar si la estrategia de acción que los actores públicos y privados han seleccionado para dirigir las situaciones sociales de su interés cuenta con las condiciones cognoscitivas, organizativas y gerenciales básicas para asegurar su eficacia, eficiencia y calidad. Los dos tipos de problema señalan el riesgo político-institucional de que el gobernar en red pierda naturaleza pública o el riesgo político-administrativo de que el gobernar en red sea inconcluyente por la dificultad de coordinar a un conjunto diferenciado de actores con diversos intereses y niveles de poder y generar los acuerdos básicos para realizar la propuesta de gobernanza.

Las dos cuestiones son genuinas y, desde nuestra perspectiva, la evaluación es la actividad fundamental para identificar si y en qué medida las propuestas y prácticas de gobernanza acreditan carácter público, legitimidad política y eficacia directiva. En esta última sección del artículo, elaboraremos una propuesta acerca de los contenidos de la gobernanza que han de evaluarse y de los criterios o referencias desde los cuales han de ser evaluados. Dicho de otro modo, expondremos de manera general y sucinta cuáles elementos son de necesaria consideración y deben estar presentes en la evaluación de la gobernanza.

Utilizando la tipología de evaluaciones según la fase de la acción pública a evaluar, se puede establecer que se puede y debe evaluar, en primer lugar, el diseño o conceptualización de la propuesta de la gobernanza, que implica valorar tres dimensiones:

a) conocer si y en qué grado el proceso de diseño de la propuesta directiva puede ser considerado propiamente un proceso de coproducción público-privada / gubernamental-social, un diseño elaborado en modo de gobernanza;

b) conocer si y en qué grado el contenido del diseño, la intencionalidad y causalidad de la propuesta de gobernanza (atender un problema social, realizar un futuro de interés social), posee propiamente naturaleza pública, es políticamente legítimo;

14 Ver punto 4 sobre la responsabilidad única de los gobiernos al otorgar carácter público al modo de gobierno en que participan diferentes actores no gubernamentales. 
c) conocer si y en qué grado su causalidad es técnica y administrativamente confiable, posee la capacidad de producir los objetivos preferidos y transformar la intencionalidad en un hecho social.

Dicho de otro modo, en esta fase evaluativa primera y crucial, se trata de evaluar si existe realmente gobernanza (o sólo una retórica) y si ésta es públicamente fundada y técnicamente robusta. Concretamente habría que incluir preguntas y elaborar indicadores relacionados con las características esenciales de ese modo de gobierno (por ejemplo, evaluar si se han establecido los canales formales para la participación de los ciudadanos, si son los adecuados, si se ha contado en ese diseño con los agentes económicos y sociales válidos, y si el proceso y el resultado del diseño acredita poseer las cualidades básicas de la deliberación y la acción considerada pública en un régimen democrático, además de poseer los atributos técnicos y administrativos, considerados básicos para la eficacia y la eficiencia).

En segundo lugar, se deberá evaluar el proceso de la puesta en práctica de la propuesta directiva elaborada y decidida en modo de nueva gobernanza. Aquí se valorarán cuestiones relacionadas con la implementación de la propuesta de gobernanza, prestando particular atención al buen funcionamiento de los factores que se consideraron fundamentales para la ejecución o efectuación de la propuesta (por ejemplo, valorar si los canales formales de participación realmente funcionan, si participan quienes se ha previsto y aportan los recursos acordados, o si existen mecanismos de exclusión debido a cuestiones de agenda o espacio, si los acuerdos tomados sobre las pautas de coordinación, actuaciones conjuntas y aporte de recursos si son los adecuados y se cumplen, si las acciones, recursos e instrumentos que los participantes emplean durante la implementación favorecen la realización de los objetivos proyectados, acreditan ser eficaces). Por último, la evaluación deberá enfocarse a los resultados de la gobernanza, tanto en su vertiente de outputs o "productos" (por ejemplo, acuerdos tomados, actuaciones conjuntas, recursos compartidos, bienes y servicios con las especificaciones de calidad aprobadas) como en su vertiente de outcomes o efectos (por ejemplo, una atención más participada e integral a los problemas públicos encarados en la acción pública y cambios en las condiciones sociales).

En el cuadro 1 que se presenta a continuación se establece una clasificación, apuntando los nuevos objetos de evaluación en el marco de la Gobernanza que se presentan y consideran en esta sección, según el tipo de evaluación (diseño, proceso y resultados) apuntado anteriormente ${ }^{15}$.

15 Agradecemos de manera muy especial a Eduardo Zapico Goñi la elaboración de este cuadro, así como su generosa cesión y sugerencia de inclusión en este artículo. 


\section{CUADRO 1}

Objeto de la evaluación en el marco de la gobernanza

\begin{tabular}{|c|c|c|}
\hline $\begin{array}{c}\text { Evaluación del diseño } \\
\text { de la gobernanza }\end{array}$ & $\begin{array}{c}\text { Evaluación } \\
\text { de la organización, procesos } \\
\text { e instrumentos } \\
\text { de gobernanza }\end{array}$ & $\begin{array}{c}\text { Evaluación } \\
\text { de los resultados } \\
\text { de la gobernanza }\end{array}$ \\
\hline $\begin{array}{l}\text { - Validez y legitimidad } \\
\text { político-institucional } \\
\text { _ Existencia y robustez de } \\
\text { los componentes } \\
\text { institucionales y técnicos } \\
\text { de la gobernanza (como } \\
\text { condiciones mínimas } \\
\text { necesarias) } \\
\text { - Sistema de gobernanza } \\
\text { co-diseñado; naturaleza } \\
\text { pública de su contenido, } \\
\text { transparencia y exigencia } \\
\text { de responsabilidades } \\
\text { - Eficacia del proceso de } \\
\text { diseño de de Gobernanza } \\
\text { Accesibilidad, } \\
\text { representatividad y } \\
\text { reconocimiento social, } \\
\text { canales formales de } \\
\text { participación activa } \\
\text { deliberación abierta, } \\
\text { transparencia y coherencia } \\
\text { de la acción conjunta en el } \\
\text { diseño de la gobernanza }\end{array}$ & $\begin{array}{l}\text { - Marco político- } \\
\text { organizativo } \\
\text { - Procesos de dirección en } \\
\text { red (criterios de elección, } \\
\text { procesos de participación } \\
\text { e interacción y } \\
\text { coordinación, canales de } \\
\text { información y consulta, } \\
\text { co-financiación, métodos } \\
\text { de resolución de } \\
\text { conflictos, co-decisión, } \\
\text { construcción y fomento } \\
\text { de acuerdos } \\
\text { multilaterales) } \\
\text { - Marco técnico } \\
\text { organizativo } \\
\text { - Capacidad de } \\
\text { coordinación, pertinencia } \\
\text { y cohesión del } \\
\text { partenariado o de la red, } \\
\text { soporte de argumentos } \\
\text { sobre previsiones o } \\
\text { evidencias del mérito de } \\
\text { las decisiones }\end{array}$ & $\begin{array}{l}\text { - Aumento de la } \\
\text { participación } \\
\text { - Acuerdos tomados, } \\
\text { acciones conjuntas, } \\
\text { efecto multiplicador en la } \\
\text { aportación de recursos } \\
\text { privados } \\
\text { - Consensos sobre temas y } \\
\text { acciones de gobierno } \\
\text { - Visión compartida de } \\
\text { problemas conceptos y } \\
\text { temas de políticas } \\
\text { públicas } \\
\text { - Creación y desarrollo de } \\
\text { redes de trabajo } \\
\text { (densidad, cercanía, ver } \\
\text { GAPP, nº 1, Nueva Época) }\end{array}$ \\
\hline
\end{tabular}

Fuente: Eduardo Zapico Goñi (no publicado).

Aunque es necesario y conveniente evaluar el proceso de la gobernanza en su ciclo global de diseño, implementación y resultados, a fin de que no sea un concepto imaginado de gobierno posible o un concepto prescriptivo sin referente o viabilidad real, consideramos que la evaluación del diseño del contenido de la gobernanza es una actividad indispensable y crucial para la validación teórica y práctica de la misma. Lo que aquí se propone como la evaluación del proceso de diseño o elaboración de la gobernanza no es igual al ejercicio habitual de evaluación que trata de conocer los efectos de las acciones, comparados con sus efectos proyectados, exigidos o esperados. Es un modo de evaluación que "mide" o verifica la correspondencia de la acción que se lleva a cabo factualmente con los estándares, requisitos o especificaciones

42 normativas de la operación considerada correcta, apropiada u óptima en términos 
institucional-políticos y, derivadamente, en términos de su eficacia-eficiencia causal. Concentra su mirada valorativa más en la validez, la propiedad o la calidad de la acción que en los efectos de la acción. Es una comparación entre la acción como se desarrolla y la acción como debe ser o como se exige que sea. Lo específico de la evaluación del diseño consiste en ser una actividad que examina y valúa una realidad con referencia a ciertos valores o criterios valorativos vigentes o previamente establecidos, a fin de conocer su contradicción o identificación con ellos, su mayor o menor grado de conformidad con los atributos o requisitos de los valores de referencia, generando información para identificar el tipo y la magnitud de la brecha entre la realidad y el valor, así como las causas que lo provocan.

En nuestro caso la evaluación se orienta, primero, a identificar en qué medida el proceso real de diseño de la gobernanza cumple con los requisitos distintivos que el concepto de gobernanza implica (tales como deliberación y decisión asociada o en red entre las autoridades públicas y sectores del público ciudadano) de modo que se pueda determinar si y en qué medida existe gobernanza en sentido propio y no se presente artificialmente como tal un proceso directivo gubernamentalmente dominado o capturado por grupos sociales o privados poderosos. En conexión, la evaluación busca principalmente registrar la contradicción, la deficiencia o el grado de conformidad del diseño de la gobernanza con los valores políticos-institucionales que el acto público de gobernar implica y exige, determinando si y en qué grado estos valores son respetados o dejados de lado en el proceso y resultado del diseño. Por último, la evaluación puede orientarse a calificar, si es posible, el grado de calidad técnica del diseño, la mayor o menor conformidad de sus supuestos con los requisitos cognoscitivos, tecnológicos, organizativos y administrativos que se exigen para que sea eficaz y produzca resultados.

Para la evaluación del diseño de la gobernanza se pueden elaborar o están a disposición numerosos indicadores empíricos que emplean los estudios interesados en determinar y ponderar las características de la acción de un gobierno o de un país, como la calidad institucional, la eficacia y honestidad del sistema judicial y policial, la calidad de la democracia, la transparencia, la incorrupción, el capital social, el desarrollo humano, la gobernabilidad, la seguridad, la estabilidad política, la libertad económica, etc. Un esfuerzo recapitulador de estos indicadores de calidad del gobierno o de un país más que de eficacia y eficiencia de políticas y programas públicos es el ofrecido por los indicadores del Banco Mundial sobre "Gobernanza y Calidad Institucional".

A pesar de su importancia, este ejercicio evaluativo del proceso de diseño de la gobernanza no representa la actividad última ni pone punto final a la evaluación, sino con frecuencia se ve obligado a avanzar hacia un tipo de evaluación más profundo y determinante pero también más exigente informativa, analítica, valorativa y políticamente. Esto ocurre cuando el juicio de la evaluación sobre las eventuales contradicciones o deficiencias del proceso de diseño de la gobernanza no es aceptado a menos que la evaluación se adentre también a examinar y validar los componentes institucio- 
nales de la estructura del proceso de gobernanza y se pregunte si los componentes institucionales vigentes deben ser considerados como las referencias valorativas últimas y los estándares normativos incuestionables de la acción de gobierno o si, en cambio, manifiesten ellos a su vez deficiencias, incoherencias, omisiones, equivocaciones... que en la práctica bloquean potencialidades de mejor gobierno público, razón por la cual procede examinar y depurar sus estándares y sistemas normativos a fin de que se constituyan en referencias normativas genuinas y plenas, que expanden en vez de coartar las potencialidades y alcances de gobierno.

En efecto, muchos cuestionamientos que se hacen a la validez de la gobernanza en asociación o en red considerándola una actividad directiva impropia, institucionalmente contradictoria con los valores públicos y hasta ilegal, al ser analizados con mayor precisión, terminan por remitir a examinar la referencia de valor con la que es comparada la gobernanza a fin de valuar su grado de corrección política, pues la manera convencional o dominante de entender la referencia suscita cuestiones y dudas sobre su calidad de referencia definitiva. Por ejemplo, ciertas formas de participación ciudadana en la formulación e implementación de las políticas o los programas públicos, que acreditan responsabilidad pública y eficacia real, han sido cuestionadas o minusvaloradas por el concepto dominante de la decisión pública entendida como una acción exclusivamente gubernamental o el de representatividad política entendida sólo como un efecto electoral partidario o el de control del poder público entendido como una actividad propia y exclusiva de los otros poderes públicos o el de administración pública entendida como actividad exclusiva de las burocracias formales. EI choque que se presenta en muchos países entre las prácticas directivas que sigue el gobierno y los diseños institucionales vigentes o clásicos, además de provocar interminables polémicas, ocasiona desafortunadamente que gobiernos y ciudadanos terminen en la práctica por formular interpretaciones legales casuísticas o artificiosas para justificar sus conductas y darles la vuelta a reglamentos y normas sin caer en infracciones abiertas.

Las referencias valorativas institucionales de la gobernanza son, como previamente expuesto, el diseño que define las facultades, responsabilidades y relaciones de los poderes públicos, el sistema de justicia y policía, las instituciones de mercado y de la sociedad civil, las instituciones internacionales. Cada uno de estos campos institucionales tienen atributos, propiedades, requisitos, estándares específicos, que son como la referencia valorativa con la se comparan el diseño y aun la ejecución de las acciones de gobernanza para calificarlas, pero el escrutinio de la valoración puede concluir que esos atributos, requisitos y estándares de valor no lo son tanto, sino que son a su vez inapropiados, defectuosos o por lo menos discutibles, por lo que pueden ser reinterpretados conceptualmente y reformados para constituirse en genuinas y últimas referencias de valor. Sobrarían ejemplos para marcar las impropiedades o deficiencias que para una gobernación eficaz y socialmente respetada y confiable muestran los ordenamientos reglamentarios de los parlamentarismos o presidencialismos, o los de los sistemas de justicia y de policía, o el cuerpo de las leyes que regu44 lan a la administración pública y a los mercados o las libertades de la sociedad civil. En 
suma, hay muchas ideas de invalidez político institucional de la gobernanza que provienen de las tradiciones políticas y las características actuales de las instituciones públicas, las cuales pueden plasmar concepciones y prácticas anquilosadas o parciales. En este sentido, la evaluación, además de calificar el proceso de gobernanza de acuerdo a su mayor o menor grado de conformidad con el marco valorativo del estado democrático, representa un instrumento heurístico y analítico que conduce a examinar honestamente las actuales instituciones, descubrir sus limitaciones y señalar las tensiones que se presentan entre las necesidades directivas de gobierno y una estructura institucional rígida o desfasada.

La evaluación de la calidad y robustez de los componentes institucionales y de los componentes técnicos descritos en el punto 3 (el sistema de ciencia-tecnología, las finanzas públicas, la política pública y la administración pública) es decisiva y constructiva, pues los depura, valida y convierte en los factores estructurales "previos" de la gobernanza, que a modo de "condiciones mínimas necesarias" de su existencia, operación y validez van a determinar con mucho las posibilidades y el éxito de la gobernanza. Dicho al margen, la evaluación puede constituirse en la actividad decisiva para encontrar y validar los factores, normas o principios de lo que algunos autores comienzan a llamar "metagobernanza", es decir, las condiciones que aseguran que la gobernanza sea un proceso genuino de dirección de la sociedad. La evaluación de la gobernanza incluye explícita o implícitamente la referencia a dichos componentes estructurales, pero su foco específico y sustantivo de atención es el proceso mediante el cual autoridades públicas y actores sociales diseñaron interdependientemente el contenido o la propuesta de la gobernanza (que se plasma en políticas, programas, leyes, asignaciones de recursos...), para conocer y calificar tanto su validez institucional como su idoneidad causal.

En el terreno de la validez político-institucional de la gobernanza, las cuestiones giran casi todas alrededor del carácter público de sus actividades y resultados y se enfocan a evaluar si el interés público es preservado o ha sido distorsionado. No faltan planteamientos prejuzgados que suponen ideológicamente que la gobernanza posee una estructura que la condena intrínsecamente a distorsionar el fin público por el simple hecho de ser resultado de decisiones asociadas del gobierno con el sector privado y social. Sin embargo, son de tomarse en serio los cuestionamientos que apuntan a las reales, posibles o eventuales fallas de naturaleza pública de la gobernanza, que se presentarían todas las veces que la decisión de gobierno es capturada por poderosos intereses privados o sociales que en su participación no persiguen propósitos públicos (ni siquiera como fines intermedios), o cuando en las decisiones públicas es notoria una injusta desigualdad en la participación de los ciudadanos (hay grupos que tienen fácil acceso a la deliberación pública y ciudadanos excluidos que carecen de voz e influencia) o cuando es considerada ilegítima la representatividad de los grupos privados o de las organizaciones laborales y civiles que el gobierno reconoce como sus interlocutores y socios en sus decisiones y operaciones, etc. Los cuestionamientos sobre la naturaleza pública de las decisiones de gobierno no son exclusivos de la gobernanza, sino son la cruz permanente de cualquier actividad de 
gobierno, como lo muestran las controversias en el análisis de políticas públicas, en finanzas públicas, en el proceso de aprobación de las leyes públicas, en los programas de la administración pública, etc.

Otros puntos significativos a evaluar en el terreno político-institucional de la gobernanza son la calidad de la participación ciudadana, así como la transparencia del proceso y la rendición de cuentas de sus conclusiones. En el campo de la participación, resulta especialmente importante valorar los posibles procesos de inclusión y exclusión de los diferentes actores sociales y económicos. Efectivamente, es previsible que carezcan de aceptación social y, por ende, se condenen a la ineficacia por invalidación política aquellas decisiones directivas en las que se puede observar que son bloqueados o excluidos grupos de ciudadanos involucrados y expertos en el tema, dispuestos a participar sin ir tras provechos particulares, o en las que los intereses privativos de determinados actores privados y sociales han alcanzado una cuestionable dominante influencia en la elaboración de la forma que tomará la gobernanza. Asunto crítico particular es el de la reputación social de los actores que participan con el poder político en la elaboración de las decisiones públicas. Puede haber asuntos en los que la representatividad y la reputación social de los participantes (autoridad intelectual o moral, espíritu público probado, trayectoria cívica conocida, confiabilidad...) pudiera no ser determinante, como tal vez ocurra en los proyectos de creación de infraestructura, en los que lo está principalmente en juego es el aporte financiero, tecnológico y gerencial de los socios privados, pero hay otros asuntos de interés público (los de desarrollo regional, los ambientales, los laborales, por ejemplo), en los que el tema de la representación y reputación social es determinante y clave para la validez de la decisión. Socios del gobierno, que fueran socialmente objetados por sus negras trayectorias y pautas de conducta, perjudicarían de entrada la calidad institucional-política de la decisión y despertarían sospechas de "captura del estado”, de corrupción pública, de complicidad clientelista... etc. Lo mismo sucederá si los que participan en las decisiones públicas no pueden acreditar suficiente representación social, puesto que no son ni directivos ni delegados ni miembros sobresalientes de organismos empresariales, organismos civiles (de profesionales, de expertos, de oficios, de centros académicos... ), organizaciones de la comunidad local o no gubernamentales.

En el terreno de la transparencia, va de suyo que deberían existir prácticas o normas a fin de que los ciudadanos interesados puedan informarse sobre las condiciones para participar en el proceso de diseño, sobre el perfil de los participantes en el diseño de la propuesta de gobernanza, sobre el modo como definieron el asunto a tratar y sobre las razones que los participantes en la decisión emplearon para considerar que esa propuesta era la conveniente o necesaria, etc. Asimismo, en la rendición de cuentas, los gobernantes y sus socios deberían ofrecer explicaciones sobre cuáles actores han sido incluidos y excluidos en el proceso y cuáles fueron las razones para ello. Por ejemplo, ¿ha existido voluntad de incluir a grupos de actores que normalmente no ostentan ni están en posiciones de poder y que, sin embargo, tienen el 46 conocimiento, la autoridad moral, la confianza de núcleos de población? 
En el terreno de la validez técnica son también numerosas las interrogaciones sobre el proceso decisorio o de diseño de la gobernanza, relacionadas con su posibilidad de existencia y su eficacia. Dos empero parecen ser las cuestiones relevantes, una más político-gerencial y otra más propiamente gerencial. La primera cuestión se refiere a las condiciones que facilitaron el acuerdo entre los participantes, que es la condición para que pueda existir, desarrollarse y concluir un proceso de dirección asociada, en red o colegiada, y que incluye la evaluación de la calidad de las prácticas de coordinación durante el proceso de deliberación de muchos actores con diferentes posiciones. La segunda cuestión, más científico-técnica, se pregunta sobre la validez causal (eficacia-eficiencia) del contenido de la propuesta de gobernanza, que es el resultado del proceso de diseño en asociación.

La primera cuestión, que se pregunta sobre la forma como se organiza y dirige el proceso a fin de hacer posible la construcción de los acuerdos es fundamental, porque el proceso de elaboración de la gobernanza, siendo una acción colectiva en la que participan múltiples actores con diferentes intereses y con diversos niveles de conocimiento, poder y recursos, no podrá ponerse en movimiento ni desplegarse a menos que existan acuerdos firmes entre los participantes (públicos, privados y sociales) acerca de las reglas de acceso para participar en el proceso y acerca de las reglas y prácticas (de interacción, interlocución, coordinación...) que habrán de observarse a lo largo del proceso. Desacuerdos en esos dos puntos capitales hacen imposible que el proceso comience, se despliegue y concluya. La gobernanza no puede existir y menos ser eficaz sin construcción de acuerdos mediante todos los dispositivos de entendimiento posibles y considerados válidos ${ }^{16}$. Por consiguiente, es necesario identificar cuáles son las condiciones que hacen posible y aun facilitan el acuerdo en situaciones de acción colectiva con pluralidad de posiciones y capacidades de los participantes, de modo que la producción de la propuesta de gobernanza no sea un proceso azaroso, anecdótico, que se desenvuelve sobre la marcha, no planificable ni conceptualizable ni susceptible de conducción. El aporte central de la evaluación en este punto es ofrecer elementos comprobables que valoran la existencia y el grado de la cooperación, así como identifican sus condiciones e incentivos. Sobre cooperación y confianza existe una extensa literatura, y habrá que producir los indicadores mensurables de las prácticas que generan cooperación o insolidaridad y de las que, por sus costes de transacción, generan deserción y oportunismo.

La segunda cuestión señala otro problema. El acuerdo sobre el inicio, desarrollo y conclusión del proceso puede lograrse de diversos modos o mediante diversas herramientas según las reglas y prácticas que se hayan aceptado durante el proceso. Sin embargo, para responder apropiadamente a la cuestión de la capacidad y eficacia

16 Es lógico que el consenso acerca del proceso de decisión y de su producto sea ahora el factor fundamental de la validez y efectividad de la gobernanza y ya no el consenso alrededor del sujeto que decide, el gobernante, ya que éste es ahora una dirigencia colegiada, integrada por una autoridad legítima y por ciudadanos que no son autoridades públicas, pero tienen el derecho legítimo y el interés cívico de involucrarse en los asuntos públicos, además de ser poseedores de recursos que son clave para conducir a la sociedad hacia las situaciones de valor deseadas. 
directiva de los gobiernos, la referencia al conocimiento causal (modelos, teoremas, tecnologías, mejores prácticas... ) y a administraciones competentes y expertas es una condición básica. Es poco defendible pensar que un proceso decisorio, cuyas reglas y prácticas hayan marginado a grupos conocedores del problema, no hayan exigido argumentos y evidencias en la discusión ni exigido tampoco cálculos de asignación eficiente de recursos... puedan dar origen a una propuesta de gobernanza eficaz y eficiente en la solución de problemas públicos y en la realización de las situaciones sociales preferidas ${ }^{17}$. Los modelos decisorios de transacción política frente a determinados problemas o futuros de sociedad pueden servir para sostener la aceptabilidad social y viabilidad política de una propuesta de gobierno, sea una política o programa o proyecto, pero difícilmente para mostrar y fundar su eficacia. Sirven tal vez para evitar conflictos e inestabilidades políticas, que seguramente harían más difícil encontrar la posibilidad de resolver un problema, pero no para crear las condiciones de su solución efectiva.

Estas dos cuestiones, para encontrar una respuesta, suponen un marco de referencia. En lo que respecta a nuestras creencias causales, las cuales sustentan la eficacia y eficiencia de las acciones, el sistema de ciencia y tecnología constituye una referencia estable y probada, aun si el gobernar aborda con frecuencia problemas y situaciones en las que no hay teoría o modelos probados, pero en lo que respecta a la formación de acuerdos en situaciones de interlocución pluralista e independiente no disponemos aún de un marco de referencia, con excepción de formulaciones de sistemas de ética comunicativa, que es válida para la comunicación en el ámbito de los asuntos públicos. Es precisamente de nuevo la evaluación en su "uso conceptual" el ejercicio analítico apropiado, a pesar de la ausencia de una referencia firme (teórica y ética) sobre la formación del acuerdo, debido a que el proceso de decisión pública, además de estar condicionado necesariamente por factores políticos, aborda frecuentemente situaciones en las que la determinación de la causalidad idónea no es probada o es desconocida.

Por lo tanto, el ejercicio de evaluación del proceso de dirección de la sociedad en modo asociado o en red parece implicar:

1) el diagnóstico de la situación evaluativa y la identificación de las necesidades informativas de los diferentes actores involucrados en el proceso de decisión o de ejecución de la decisión;

2) el establecimiento de los temas a evaluar, sus dimensiones y sus criterios, que pueden y deben ser consensuados por la instancia evaluadora con dichos actores involucrados;

17 El análisis de políticas públicas, a partir de su estudio del proceso de decisión de las políticas, permite elaborar un espectro de posibilidades decisorias, que se mueven desde la modalidad de la racionalidad estricta maximizadora y costoeficiente hasta la simple transacción política sin razones, pasando por modalidades decisorias de "racionalidad limitada" (incrementalismo, análisis como artesanía o de la máxi-

48 ma racionalidad posible, análisis con partido tomado o de racionalización de posiciones...). 
3) la recopilación y análisis sistemático de evidencias e información de diferente naturaleza a partir de diferentes fuentes documentales, sociales, demoscópicas, etc.; y

4) la valoración sistemática de los criterios previamente establecidos y de las referencias conceptuales y normativas que orientan la evaluación y le otorgan su sistema de medición.

Este ejercicio integral puede extraer conclusiones, recomendaciones y lecciones aprendidas, que contribuirían a la mejora y la rendición de cuentas de los gobiernos acerca del modo como dirigen y de sus resultados, así como puede contribuir al desarrollo conceptual y al establecimiento de un marco de referencia que podrá ser utilizado en un futuro.

Por la propia naturaleza de la gobernanza, al ser un modo de dirección en red con diferentes actores parece adecuado sugerir una mirada especial a enfoques de evaluación pluralistas y participativos, tales como la propuesta de Monnier el cual basa la utilidad social de la evaluación y su legitimidad política en la propia participación de los actores en los procesos de evaluación (Monnier, 1995). De esta manera, la evaluación se convertiría, además, en otro elemento integrante más -y de carácter esencial- de dicho modo de dirección.

\section{A MODO DE CONCLUSIÓN}

Por todo lo dicho, la evaluación de la gobernanza está sujeta a experimentación y validación, debido tanto a la novedad de dicha actividad directiva, como a que, desde un plano más tecnogerencial, se pueden carecer de referencias causales seguras en varios casos sociales y porque la referencia a una ética comunicativa es algo opcional y exigible pero no vinculante. No obstante estas limitaciones, la evaluación, tanto en su vertiente más política-institucional como tecnogerencial es una actividad necesaria y fructífera para que el gobernar en modo de gobernanza sea considerado una actividad aceptable y valiosa, por lo que podría contemplar la tarea de construir un marco de referencia valorativo sobre las condiciones mínimas necesarias y los componentes básicos de una estructura de gobernanza, los requisitos que son básicos e imprescindibles para lograr acuerdos en relaciones de interlocución pluralista e independiente, así como construir un marco de referencia de los requisitos que son básicos e imprescindibles para el aprendizaje causal o de idoneidad causal, cuando las evaluaciones muestran las ineficacias y errores de las políticas y programas. Si la evaluación, a partir de sus resultados, emprendiera esta actividad intelectual contribuiría no sólo a decirnos que los actos de gobierno no funcionan por la impropiedad y la ineficacia de sus acciones (incluso también detectando y dando a conocer los actos de gobierno que sí funcionan), sino también produciría pensamiento positivo que contribuiría a mejorar la capacidad y eficacia directiva de los gobiernos. 
De esta manera, la evaluación de la gobernanza tal y como aquí se ha planteado, cumpliría de lleno las funciones que le han sido encomendadas: no sólo contribuiría a la rendición de cuentas y responsabilidades de los gobiernos, sino que también sería un eficaz ejercicio para la mejora del proceso directivo de gobierno y para iluminar o ilustrar a los gobiernos y actores sociales, a través del mejor conocimiento y entendimiento de ese modo de dirección, mejores maneras de proceder hacia la consecución de los futuros deseados. Así, dicha evaluación podría ser útil no sólo y en palabras de Weiss, en términos "instrumentales" (arrojando información útil que puede ser utilizada de forma directa en la mejora y la rendición de cuentas), "conceptuales" (contribuyendo a la mejor definición y comprensión de la gobernanza) y "persuasivos" (ayudando a conseguir los apoyos necesarios para que dicho modo de gobierno sea posible y aceptado en el medio intelectual y político), sino también y sobre todo en términos "sociales" otorgando a la evaluación lo que en palabras de Monnier es la finalidad última de la evaluación, es decir su "utilidad social”, que sólo es posible con el reconocimiento de la complejidad de la realidad y el contexto en el que se da la gobernanza, y con la participación de los actores involucrados en la acción pública.

En conclusión, la evaluación puede ser entonces, además de una herramienta para la mejora de la gobernanza, un elemento integrante propio de dicho modo de gobierno. Los gobiernos, por lo tanto, no sólo tienen la responsabilidad de la coordinación y dirección de dicha acción pública en colaboración con los diferentes actores sociales y económicos, sino de la evaluación como elemento clave para asegurar la transparencia, la retroalimentación, la mejora continua, el aprendizaje, y la rendición de cuentas. En definitiva, la evaluación se convierte pues en un instrumento democrático al servicio de la gobernanza; dicho en otras palabras, evaluar la gobernanza será por tanto una manera de evaluar el desarrollo democrático de un país.

\section{REFERENCIAS BIBLIOGRÁFICAS Y DOCUMENTALES}

Aguilar, L. F. (2006), Gobernanza y Gestión Pública. México: Fondo de Cultura Económica.

- (2009), Gobernanza: Normalización conceptual y nuevas cuestiones. Barcelona: ESADE, Cuadernos de Liderazgo, 17.

Ballart, X. (1996), “Modelos teóricos para la práctica de la evaluación de programas”. En Q. Brugé y J. Subirats, eds., Lecturas de Gestión Pública. Madrid: Ministerio para las Administraciones Públicas: 323-351.

Bevir, M. (2009), Key Concepts in Governance. Londres: Sage.

Bustelo, M. (2001), La evaluación de las políticas públicas de igualdad de género de los gobiernos central y autonómicos en España: 1995-1999. Madrid: UCM. Tesis Doctoral. Publicación electrónica.

- (2003), “Qué tiene de específico la metodología de evaluación?”, en R. Bañón comp., La evaluación de la acción y de las políticas públicas. Madrid: Díaz de Santos.

Bustelo, M. y J. Fitzpatrick (2009), “La situación de la evaluación en España. Resultados preliminares de una encuesta realizada a la comunidad evaluadora”. Ponencia presentada en el VI Seminario de Experiencias de Evaluación de Programas y 
Políticas Públicas. Magíster en Evaluación de Programas y Políticas Públicas. Centro Superior de Estudios de Gestión, UCM. Madrid, 28 septiembre. En línea: $<$ www.magisterevaluación.es>. (Consulta: 10 de febrero 2010).

Garde, J.A. (2004), "La evaluación de Políticas y su Institucionalización en España”, Gestión y Análisis de Políticas Públicas, n³ 30/31: mayo-diciembre de 2004.

Innerarity, D. (2006), El Poder Cooperativo: otra forma de gobernar. Barcelona: ESADE. Kooiman, J., ed., (1993), Modern Governance: New Government - Society Interactions. Londres: Sage.

- (2003), Governing as Governance. Londres: Sage.

Longo, F. (2008), Los principales atributos de la gobernanza en las democracias avanzadas, Barcelona, ESADE. En línea: <http://portal.esade.edu/portal/pls/portal/ docs/1/9224348.PDF> (Consulta: abril 2010).

Monnier, E. (1995), Evaluación de la acción de los poderes públicos. Madrid: Instituto de Estudios Fiscales, Ministerio de Economía y Hacienda.

Natera, A. (2004), “La noción de gobernanza como gestión pública participativa y reticular", Documentos de Trabajo Política y Gestión 2. Madrid: Universidad Carlos III de Madrid.

Pierre, J. et al. (2000), Debating Governance. Oxford: Oxford University Press.

PNUD (1997), Reconceptualising Governance, Nueva York: PNUD. En línea: <http:// www.pogar.org/publications/other/undp/governance/reconceptualizing.pdf> (Consulta: 20 de febrero 2010).

Prats, J. (2004), "De la burocracia al management y del management a la gobernanza”, Instituciones y Desarrollo, 3.

Rhodes, R.W.A. (1997), Understanding Governance: Policy Networks, Reflexibility and Accountability. Londres: Open University Press.

Sancho, D. (2009), “La evaluación de los servicios públicos externalizados: ¿qué evaluar? ¿Cómo evaluar?”. Ponencia presentada en la VI Conferencia Bienal de Evaluación de Políticas Públicas, Barcelona 6, 7 y 8 de Mayo.

Shadish, W., Cook, T., et al. (1991), Foundations of Program Evaluation. Theories of Practice. Newbury Park: Sage.

Stufflebeam, D. (2001), Evaluation Models. New Directions for Program Evaluation, 89. San Francisco: Jossey-Bass.

Stufflebeam, D., Madaus, G. y Kellaghan, T. (2002), Evaluation Models. Viewpoints on educational and human services evaluation. Boston: Kluwer Academic.

Stufflebeam, D. y Shinkfield, A. (1987), Evaluación sistemática. Guía teórica y práctica. Madrid: Paidós/MEC.

Torres, R., Preskill, H. y Piontek, M.E. (1996), Evaluation Strategies for Communicating and Reporting. Thounsand Oaks: Sage.

Vedung, E. (1997), Evaluación de Políticas Públicas y Programas. Madrid: Ministerio de Trabajo y Asuntos Sociales.

Weiss, C. H. (1998), Evaluation. Methods for Studying Programs and Policies. Upper Saddle River: Prentice Hall. 